\title{
Intra-serotype SAT2 chimeric foot-and-mouth disease vaccine protects cattle against FMDV challenge
}

\author{
Francois F. Maree ${ }^{\mathrm{a}, \mathrm{b}, *, 1}$, Peninah Nsamba ${ }^{\mathrm{c}, \mathrm{d}, 1}$, Paidamwoyo Mutowembwa ${ }^{\mathrm{a}}$, \\ Lia S. Rotherham ${ }^{\mathrm{a}}$, Jan Esterhuysen ${ }^{\mathrm{a}}$, Katherine Scott ${ }^{\mathrm{a}, \mathrm{c}}$

\begin{abstract}
a Transboundary Animal Diseases Programme, Onderstepoort Veterinary Institute, Agricultural Research Council, Private Bag X05, Onderstepoort 0110, South Africa

${ }^{\mathrm{b}}$ Department of Microbiology and Plant Pathology, Faculty of Agricultural and Natural Sciences, University of Pretoria, Pretoria 0002, South Africa

${ }^{\mathrm{c}}$ Department of Veterinary Tropical Diseases, Faculty of Veterinary Science University of Pretoria, Private Bag X04, Onderstepoort 0110, South Africa ${ }^{\mathrm{d}}$

Makerere University, College of Veterinary Medicine, Animal Resources and Biosecurity, PO Box 7062, Kampala, Uganda
\end{abstract}

Keywords:

Foot-and-mouth disease virus

Intra-serotype chimera

Chimeric antigen

Vaccine

\begin{abstract}
The genetic diversity of the three Southern African Territories (SAT) types of foot-and-mouth disease virus (FMDV) reflects high antigenic variation, and indications are that vaccines targeting each SATspecific topotype may be needed. This has serious implications for control of FMD using vaccines as well as the choice of strains to include in regional antigen banks. Here, we investigated an intra-serotype chimeric virus, vSAT2 ${ }^{\text {ZIM14 }}$-SAT2, which was engineered by replacing the surface-exposed capsid-coding region (1B-1D/2A) of a SAT2 genome-length clone, pSAT2, with that of the field isolate, SAT2/ZIM/14/90. The chimeric FMDV produced by this technique was viable, grew to high titres and stably maintained the 1B-1D/2A sequence upon passage. Chemically inactivated, oil adjuvanted vaccines of both the chimeric and parental immunogens were used to vaccinate cattle. The serological response to vaccination showed the production of strong neutralizing antibody titres that correlated with protection against homologous FMDV challenge. We also predicted a good likelihood that cattle vaccinated with an intra-serotype chimeric vaccine would be protected against challenge with viruses that caused recent outbreaks in southern Africa. These results provide support that chimeric vaccines containing the external capsid of field isolates induce protective immune responses in FMD host species similar to the parental vaccine.
\end{abstract}

\section{Introduction}

Foot-and-mouth disease (FMD), of which FMD virus (FMDV) is the causal agent, is a highly infectious vesicular disease of cloven hoofed animals such as cattle, pigs, sheep, goats and other artiodactyl species. Although mortality rates are generally low, morbidity is high and in the event that an FMD outbreak occurs, it results in severe economic losses to the livestock industry, especially in FMD-free regions of the world [1-3]. The disease is widely distributed in the developing world, in particular Africa, Asia and South America $[2,4]$. In these regions, livestock farming forms the backbone of rural economies that supports approximately $70 \%$ of the world's poor [5]. FMD outbreaks particularly affect vulnerable

\footnotetext{
* Corresponding author at: Transboundary Animal Diseases Programme, Onderstepoort Veterinary Institute, Private Bag X05, Onderstepoort 0110, South Africa. Tel.: +27 12529 9575/84; fax: +27 125299595 .

E-mail address: mareef@arc.agric.za (F.F. Maree).

1 These authors contributed equally to this work.
}

individuals such as women and children since approximately 75\% of livestock in Africa are raised under the communal smallholder systems that sustain livelihoods of these groups [6-8].

The epidemiology of FMD in Africa is influenced by two different patterns i.e. a cycle involving wildlife, in particular the African buffalo (Syncerus caffer), and an independent cycle maintained within domestic animals [9-12]. Another unique feature of FMD epidemiology in Africa is the presence of the three Southern African Territories (SAT) serotypes, i.e. SAT1, SAT2 and SAT3, with multiple genetics and antigenic variants in different geographical regions, defined as topotypes [9,13-16]. All three SAT serotypes are main-tained within the African buffalo populations $[9,13]$. The presence of large numbers of African buffalo provides a potential source of sporadic infection to domestic livestock and other wildlife species [17-19]. Although the precise mechanism of transmission of FMD from buffalo to cattle is not well understood, it is facilitated by direct contact between these two species. Once cattle are infected they may maintain SAT infections without the further involvement of buffalo [18,19]. 
Control of FMD in sub-Saharan Africa revolves around four integrated activities, i.e. vaccination of cattle in high risk areas; physical separation of infected wildlife and susceptible livestock; movement restriction and surveillance. Vaccines are based on chemically inactivated whole virus antigen combined with mineral oil adjuvant or aluminium hydroxide/saponin. Despite successful application in the developed world, the effective administration and optimal induction of protective immunity by the vaccines are hampered by several factors in developing countries. These include poor duration of protective immunity [20], the inability to prevent a sub-clinical persistent infection $[21,22]$, biophysical stability of the vaccine antigen [20], the potency of the vaccine [22] and current inactivated vaccines are often unable to control some lineages arising in these regions [23]. As a consequence countries have to rely on a thrice or quadruple annual vaccination schedule. Thus, motivat-ing for the development of structurally improved and custom-made vaccines for use in specific geographic localities [24,25]. However, development of useful cell culture-adapted vaccine strains from field isolates is time consuming and expensive, limiting the avail-ability of custom-made vaccine strains [22].

Therefore, improved vaccines, in terms of stability and anti-gen yield, especially for the control of SAT viruses in Africa and serotype $\mathrm{O}$ viruses globally are becoming a priority worldwide. One approach is to structurally design vaccines for specific geo-graphic regions $[25,26]$. The fact that the viral RNA can be made infectious in the absence of other components of the virion (reverse genetics) opened the theoretical possibility of genetically engineer-ing new viruses from in vitro-generated RNA molecules [24,27]. The introduction of specific mutations into the cloned genomes of viruses has allowed the manipulation of the biological prop-erties of field and laboratory strains and presents a promising avenue for the design of safe and effective vaccines [28-30]. We have structurally-engineered recombinant SAT viruses, containing desirable antigenic determinants and cell adaptation phenotypes [28,31,32] providing the proof-of-concept to rationally design viruses with the desired biological properties of a good vaccine strain. Several studies have shown that inter-serotype chimeric vaccines successfully induce protective immune responses and protect FMD host species against live virus challenge $[26,30,33]$. Additionally, the SAT capsid can be engineered to be thermo-stable, produce high $146 \mathrm{~S}$ antigen mass following chemical inactivation and provide appropriate immunological specificity whilst encoding the antigens required for vaccines in specific geographic localities.

This paper describes the evaluation of an intra-serotype chimeric vaccine in cattle. We assessed the serological profile gen-erated in cattle, using liquid phase blocking ELISA (LPBE) and the gold standard virus neutralisation (VN) assays as in vitro mark-ers of protection. The intra-serotype vaccine was prepared from a chimeric virus containing the external capsid-coding region of a field SAT2 isolate, ZIM/14/90, inserted in the genetic background of a SAT2 infectious clone [34]. The SAT2/ZIM/14/90 virus was iso-lated from buffalo which originated from Doma Safari area $\left(16^{\circ} 20^{\prime}, 30^{\circ} 15^{\prime}\right)$ in Zimbabwe and was selected for its potential use as a vaccine strain based on (i) initial data showing the ability to elicit an immune response that cross-reacts broadly against the three SAT2 topotype viruses from southern Africa [28] and (ii) the 9.7\%amino acid differences in the capsid proteins compare to the SAT2 infectious clone shows genetic divergence from the clone [28].

\section{Materials and methods}

\subsection{Cells, viruses and plasmids}

The SAT2 virus, SAT2/ZIM/14/90 was obtained from the FMD World Reference Laboratory (Pirbright Institute, UK) and maintained at the Transboundary Animal Diseases (TAD) (Agricultural
Research Council (ARC), South Africa). Baby hamster kidney (BHK) cells, strain 21, clone 13 (ATCC CCL-10) were maintained as described previously [29]. The SAT2/ZIM/14/90 was passaged four times through BHK-21 cells (BHK\#4) to produce a vaccine master seed stock. The variants of SAT2/ZIM/14/90 that were recovered by propagation in IB-RS-2 and BHK-21 cells as well as in cattle are shown in Fig. 1. Virus stocks were titrated by plaque assays in BHK-21 cells as described previously [22]. The BHK-21 cells were also used for RNA transfection and virus recovery of the chimeric pSAT2 ZIM14-SAT2virus [34]. The plasmid pSAT2 ${ }^{\text {ZIM14 }}$-SAT2 containing the outer capsid-coding region of SAT2/ZIM/14/90 in the PSAT2 backbone (Fig. 1) was previously constructed [34].

IB-RS-2 (Instituto Biologico renal suino) cells were maintained in RPMI medium (Sigma) supplemented with 10\% FCS (Delta Bioproducts), and were used for virus isolations and as the indicator system in the virus neutralization test (VNT).

\subsection{Production of plasmid-derived chimeric FMDV antigen and vaccine formulation}

The rescue of vSAT2 ${ }^{\text {ZIM14 }}$-SAT2 virus from a chimeric genomelength cDNA plasmid has been described before [34]. Culture fluids from SAT2/ZIM/14/90 and vSAT2ZIM14_SAT2 infected BHK-21 cells were harvested, inactivated with $5 \mathrm{mM}$ binary ethyleneimine (BEI) for $26 \mathrm{~h}$ at $25{ }^{\circ} \mathrm{C}$, clarified by centrifugation, concentrated with $8 \%$ PEG (w/v) and resolved on $10-50 \%(w / v)$ sucrose density gradients (SDG) by rate zonal centrifugation at $36,000 \mathrm{~g}$ for $16 \mathrm{~h}$ at 4 ${ }^{\circ} \mathrm{C}$. The gradients were fractionated and analyzed spectrophotometrically by measuring the absorbance at $260 \mathrm{~nm}$. Fractions containing $146 \mathrm{~S}$ virions were calculated using the extinction coefficient $E_{259 \mathrm{~nm}}=79.9$ [35] and pooled for vaccine formulation. The presence of the outer capsid proteins were verified using SDSPAGE analysis, while the integrity of the chimeric viral RNA was verified by RT-PCR and sequencing of the P1/2A-coding region.

Two separate vaccine formulations, incorporating SAT2/ ZIM/14/90 and vSAT2 ZIM14-SAT2 inactivated 146S antigens as double oil emulsions with Montanide ISA 206B (Seppic), were prepared. Each vaccine contained $3 \mu \mathrm{g} / \mathrm{ml}$ of the BEI-inactivated, SDG-purified FMDV antigen. The oil adjuvant was subsequently mixed into the aqueous antigen phase (equal volumes) at $30^{\circ} \mathrm{C}$ for $15 \mathrm{~min}$ and stored at $4{ }^{\circ} \mathrm{C}$ for $24 \mathrm{~h}$. A placebo vaccine was formulated that contained all the components, but with $1 \times$ PBS in the place of antigen.

\subsection{Cattle immunizations and viral challenge}

Fourteen naive Nguni cattle 12-18 months of age, sourced from an FMD-free zone, were divided randomly into two groups of seven animals and housed separately within the high-containment ani-mal facility at TAD (ARC-Onderstepoort Veterinary Institute). All procedures were approved by the ARC-OVI Animal Ethics Commit-tee and were performed according to national and international guidelines. The absence of antibodies to FMDV was confirmed prior to immunization. Subsequent to an initial acclimatization period, the cattle were intramuscularly vaccinated with $2 \mathrm{ml}$ of $3 \mu \mathrm{g} / \mathrm{ml}$ antigen of either the SAT2/ZIM/14/90 (group 1) or vSAT2 $2^{\text {ZIM14 }}$-SAT2 (group 2) vaccine. Two control animals were housed in a separate high-containment room and were vaccinated with the placebo vac-cine formulation that lacked viral antigen. Blood samples (10 $\mathrm{ml}$ clotted and $10 \mathrm{ml}$ heparinised blood) were collected on $0,7,14$ and 21 days post-vaccination (dpv).At 21 $\mathrm{dpv}$ the cattle from both immunized groups and the two control animals were inoculated intra-dermolingually with $1 \mathrm{ml}$ of $10^{4}$ $\mathrm{TCID}_{50}$ SAT2/ZIM/14/90 cattle-passaged challenge virus (according to the OIE approved dose of $10^{4} \mathrm{ID}_{50}$ ) (Fig. 1) into each of two sites. During each of these procedures cattle were sedated 


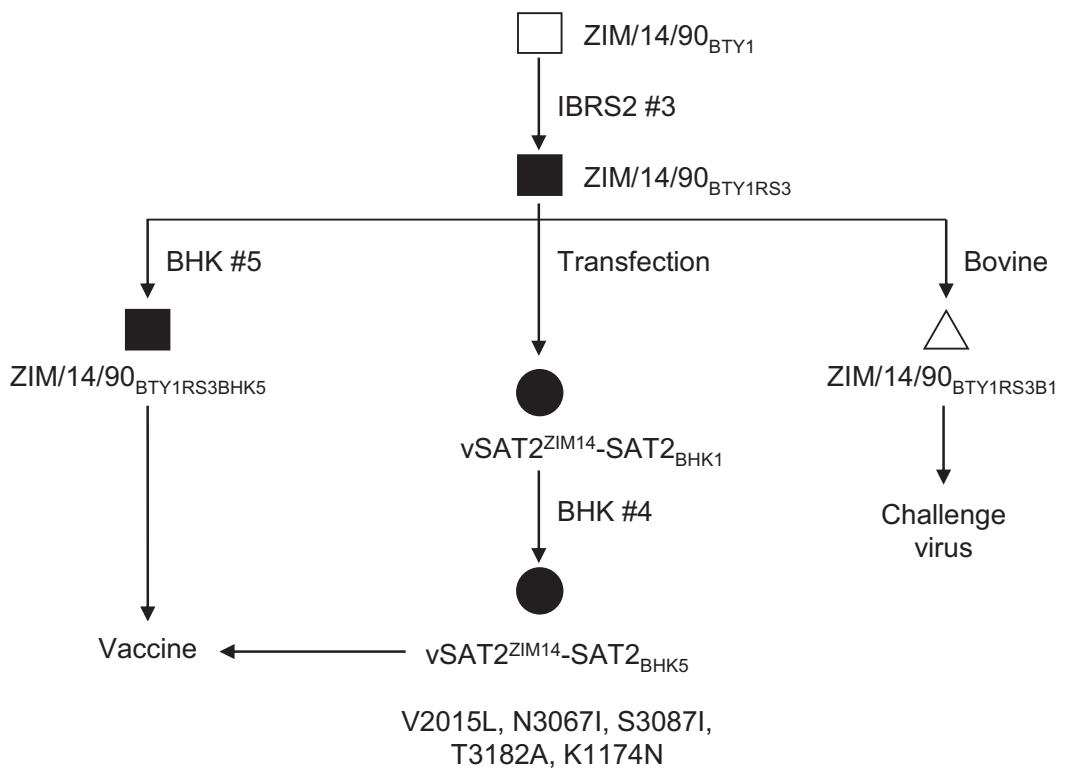

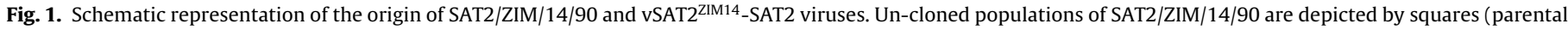

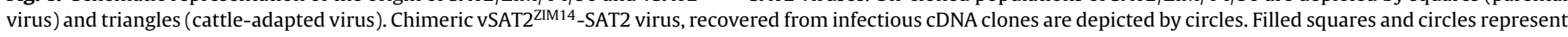

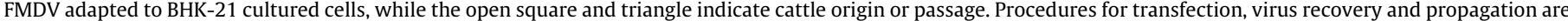

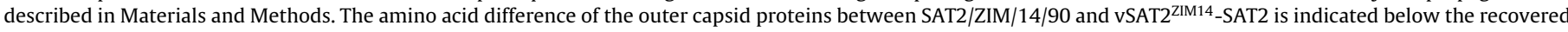
chimeric virus.

with Rompun (2\% Xylazine) at a dosage of $0.67 \mathrm{ml} / 100 \mathrm{~kg}$. Clotted and heparinised blood was collected on 0, 2, 4, 7 and 11 days post-challenge (dpc), along with oropharyngeal (OP) fluid and nasal swabs. The animals were examined daily for fever and clinical signs. Body temperatures of $39.5-40^{\circ} \mathrm{C}$ and $>40^{\circ} \mathrm{C}$ were considered as mild and severe fever, respectively. Generalization of clinical lesions was scored as follows: congestion/small lesion/healing vesicle $=1$; moderate vesicles $=2$; and severe lesion $=3$.

\subsection{Virus isolation}

FMDV in heparinised blood, OP fluid and nasal swabs was detected by the inoculation of IB-RS-2 monolayer cells as described by the Office International des Epizooties (OIE) Manual [36]. The supernatant was blind passaged at least twice or until cytopathic effect (CPE), as visualised by cell rounding and clearing of the mono-layer, was observed. A SAT2-specific antigen ELISA was used to confirm the presence of SAT2 virus in cultures showing CPE [37,38].

\subsection{Viral RNA detection by real-time quantitative RT-PCR}

The viral RNA in heparinised blood, OP fluid and nasal swabs was detected using a two-step real time RT-PCR assay. The guanidinium-silica based method described by Boom et al. [39] was used for RNA extraction. Complementary DNA synthesis from the RNA template was achieved using methods described previously by Bastos [40] using modified oligo-dT (CCATGGCGGCCGCTTTTTTTTTTTTTTT (poly-SAT-dT) primers. The real time RTPCR assays were performed using the method described in the OIE Manual [36]. Each sample was tested in duplicate.

\subsection{Liquid phase blocking ELISA (LPBE) and indirect ELISA}

Antibody titres in cattle vaccinated with either SAT2/ZIM/14/90 or vSAT2 ${ }^{\text {ZIM14-SAT2 }}$ were detected by a SAT2-specific LPBE. The LPBE was essentially carried out as described in the OIE Manual

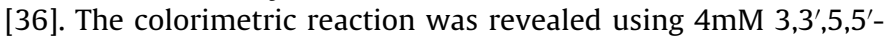
tetramethylbenzidine (Sigma-Aldrich) in substrate buffer $(0.1 \mathrm{M}$ citric acid monohydrate, $0.1 \mathrm{M}$, tri-potassium citrate; $\mathrm{pH} 4.5$ ) and $0.015 \%$ (vol/vol) of $\mathrm{H}_{2} \mathrm{O}_{2}$. The optical density (OD) at $450 \mathrm{~nm}$ was measured with a Labsystems Multiscan Plus Photometer (Thermo Fisher Scientific). Antibody titres were defined as the dilution at which $50 \%$ inhibition of the antigen OD occurred. Samples that gave serum titres of more than 1/50 were considered positive.

The IgGl and IgG2 isotype ELISAs were essentially carried out according to Capozzo et al. (1997) [41]. Maxisorp 96-well plates (Nunc) were coated with a $100 \mathrm{ng} /$ well SDG-purified 146S SAT2/ ZIM/14/90 particles. Antibodies were detected using sheep antibovine IgG1 and IgG2 HRP-conjugated antibodies (BD-Serotec, Oxford, United Kingdom) at a dilution of 1:750 and 1:1500 respectively. Serum samples were run in two-fold serial dilutions starting at 1:50. Titres were expressed as the inverse dilution reaching the cut off value $(0.2)$ calculated as mean OD +2 SD achieved by the FMDV-negative Nguni bovine serum samples $(n=30)$.

\subsection{Virus neutralization test (VNT)}

Neutralizing antibodies against SAT2/ZIM/14/90 in serum samples collected at $0,7,14$ and $21 \mathrm{dpv}$ from cattle were measured with a VNT, according to the method described in the OIE Man-ual [36] using IB-RS-2 cells in 96-well tissue culture plates. The 50\% end-point serum titres were calculated according to the method of Kärber [42]. Serum samples collected at $21 \mathrm{dpv}$ were also used to assess the neutralizing antibody response against a panel of SAT2 reference viruses and field isolates: SAT2/KNP/19/89, SAT2/ SAR/3/04, SAT2/SAR/1/10, SAT2/SAR/4/12, SAT2/NAM/1/07, SAT2/ NAM/1/08, SAT2/BOT/4/06 and SAT2/ZIM/7/83. The antibody titres were calculated as $\log _{10}$ of the reciprocal of the final serum dilution that neutralized $100 \mathrm{TCID}_{50}$ of virus in $50 \%$ of the wells [42].

\subsection{Statistical analyses}

Virus neutralization titres of sera collected from the parental and chimera vaccinated animals against SAT2/ZIM/14/90 were compared using repeated measures of ANOVA with Bonferroni 

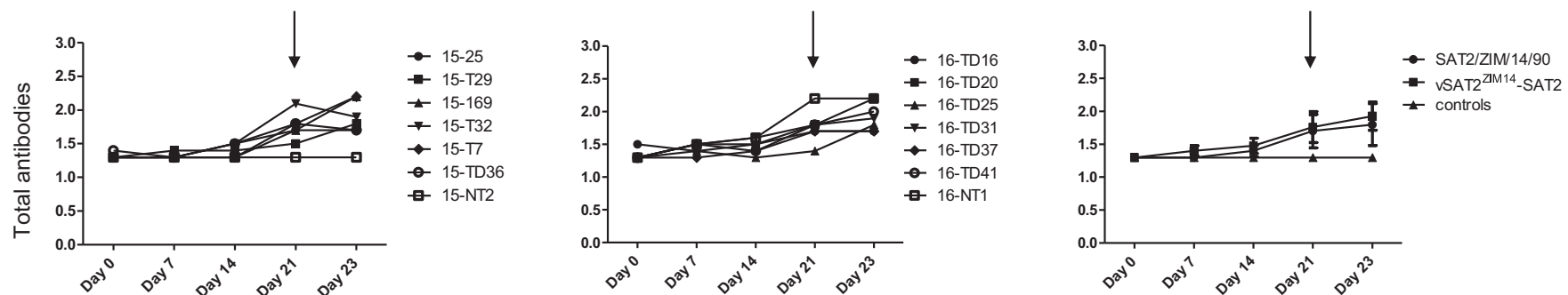

B
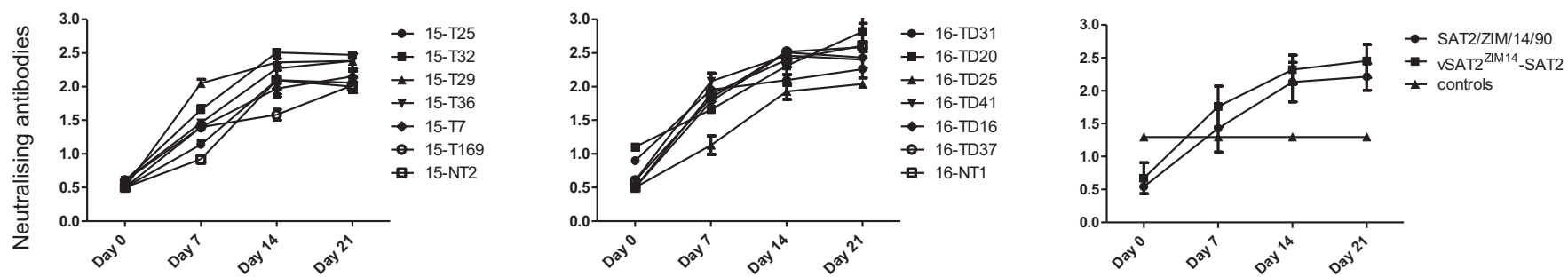

\section{Days post vaccination}

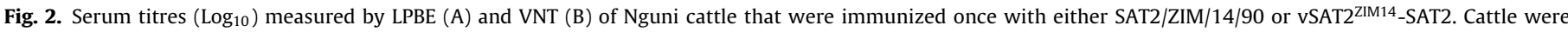
vaccinated with $6 \mu \mathrm{g}$ of either SAT2/ZIM/14/90 or vSAT2 ZIM14-SAT2 BEI-inactivated, SDG-purified antigens mixed with Montanide ISA206 adjuvant. Arrows indicate the time of challenge ( $21 \mathrm{dpv}$ ). The mean of the $\log _{10}$ LPBE titres (upper panel) or virus neutralizing tires (lower panel) and also the compared kinetics (geometric mean) are shown and the error bars represent the standard deviation. The negative control animals with $\log _{10}$ titres of lower than 1.3 are shown in the right panel.

adjustment of p values for post-hoc comparisons. All statistical analyses were performed using GraphPad Prism v5.03 for Windows (GraphPad Software, Inc.).

\section{Results}

\subsection{Characterization of SAT2/ZIM/14/90 and VSAT2 ${ }^{\text {ZIM14 }}$-SAT2}

The construction of the intra-serotype chimeric vSAT2 2 ZIM14 SAT2 virus and its antigenic profiling, growth kinetics, plaque morphologies and biophysical stability have been described elsewhere [34]. Although titres produced in BHK-21 cells were relatively low, i.e. $2-4 \times 10^{6}$, infection of BHK-21 monolayers at a multiplicity of infection (moi) of one with either SAT2/ZIM/14/90 or vSAT2 ZIM14-SAT2 resulted in the production of mature viri-ons, which sediment at $146 \mathrm{~S}$. Although experiment-to-experiment differences in the yield of BEI-inactivated $146 \mathrm{~S}$ particles were observed, there were no consistent differences in the efficiency of recovery of antigen, with a recovery of between 0.9 and $1.2 \mathrm{mg}$ for either the vSAT2ZIM14-SAT2 or the SAT2/ZIM/14/90 SDG-purified antigen in three separate experiments.

\subsection{Antibody kinetics of the SAT2/ZIM/14/90 and vSAT2 ${ }^{\text {ZIM14 }}$-SAT2 vaccines in Nguni cattle}

Sera collected on $0,7,14$ and $21 \mathrm{dpv}$ were tested by LPBE and VNT's to assess antibody titres and more specifi-cally neutralizing antibody response to vaccination. Fig. 2 shows that vaccines produced from the parental SAT2/ZIM/14/90 and chimeric VSAT2 ${ }^{\text {ZIM14 }}$-SAT2 $146 \mathrm{~S}$ particles produced a similar antibody response (Fig. 2A) and induced detectable levels of anti-SAT2/ ZIM/14/90 neutralizing antibodies as early as $7 \mathrm{dpv}$ (Fig. 2B) after a single vaccination. LPBE-tires were slightly lower compared to neutralizing antibody titres for each sampling point. Strong positive neutralizing antibody titres were observed at $21 \mathrm{dpv}$ for animals from both the groups (Fig. 2B) with titres between 2.1 to $2.8 \log _{10}$ and 2.0 to $2.5 \log _{10}$ observed for the chimera and parental vaccinated groups, respectively. No significant differences $(p>0.1)$ were seen in the neutralizing antibody titres of animals that received the vSAT2 ${ }^{\mathrm{ZIM} 14}$-SAT2 vaccine compared to animals that received the SAT2/ZIM/14/90 vaccine.

Kinetics of $\operatorname{IgG} 1$ and $\operatorname{IgG} 2$ titres at $21 \mathrm{dpv}$ were comparable between the two groups that received the parental and chimera vaccines (Fig. 3). IgG1 titres were higher than IgG2 titres at $21 \mathrm{dpv}$.

\subsection{Protection of vaccinated cattle against live SAT2/ZIM/14/90 virus challenge}

The group of seven cattle, that received the chimeric vSAT2 ${ }^{\text {ZIM14 }}$-SAT2 vaccine, were protected against systemic spread of FMD after the intra-dermolingual challenge of SAT2/ZIM/14/90 virus as observed by the absence of generalised lesions on their

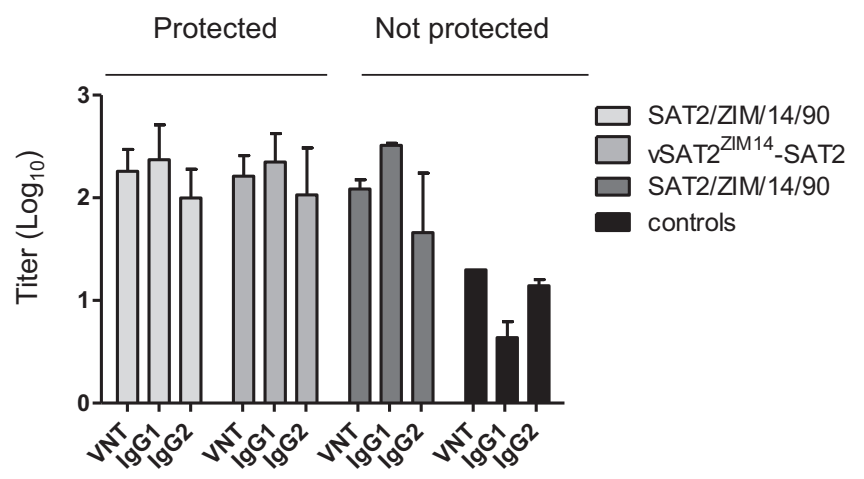

Fig. 3. Compared kinetics of the mean IgG1 and IgG2 titres and neutralizing antibody titres classified according the challenge results. The mean values and standard error of the mean are indicated. The $21 \mathrm{dpv}$ serum samples of SAT2/ZIM/14/90 ( $n=7)$, vSAT2 ${ }^{\text {ZIM14 }}$-SAT2 $(n=7)$ immunized and placebo control vaccinated $(n=2)$ animals were used with $n=13$ from protected animals and $n=2$ non-protected animals. 


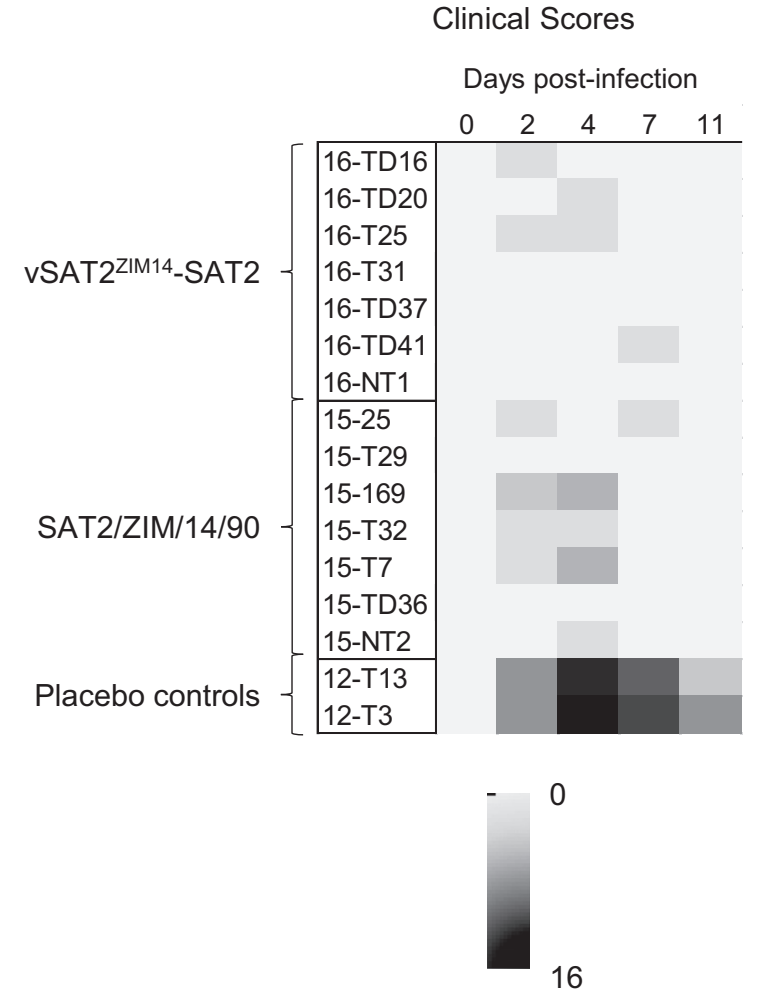

Viraemia

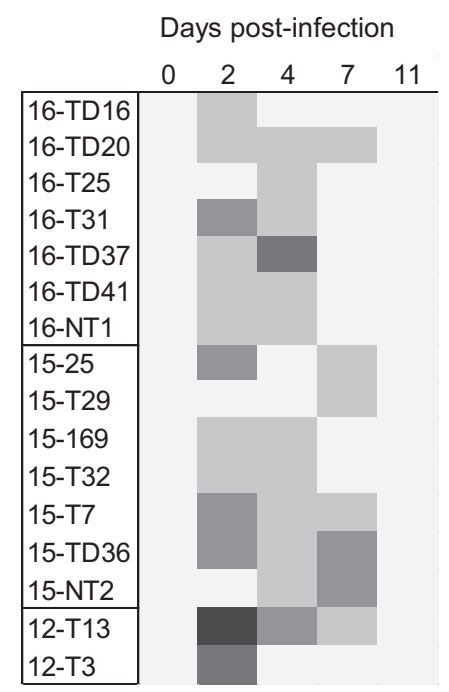

No virus and no viral RNA (Ct value $\geq 40$ ) detected

Viral RNA detected (Ct value 35-39.9)

Viral RNA detected (Ct value 30-34.9)

Virus and viral RNA detected (Ct value 25-30)

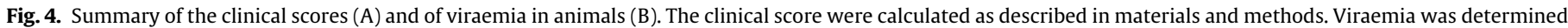
by RT-PCR on whole blood samples collected at different time points post-challenge.

hooves, whilst mild fever $\left(39.5-40{ }^{\circ} \mathrm{C}\right)$ was present in 3 of the animals, 48 h p.c. (Fig. 4A). One animal (16-T25), in this vaccination group, had severe fever $\left(40^{\circ} \mathrm{C}\right)$ for two consecutive days. However, no systemic spread of FMD was observed in animal 16-T25. This was in contrast to both the placebo vaccinated controls which devel-oped severe pyrexia and severe lesions that had generalised to all four hooves within $48-72 \mathrm{~h}$ of challenge (highest clinical score $=14$ at $4-5$ dpc; Fig. $4 \mathrm{~A}$ ).

Of the seven cattle that received the SAT2/ZIM/14/90 vaccine, two animals showed generalization with each having one lesion on one hoof (clinical scores $=3$ at $4 \mathrm{dpc}$ ). Both animals had mild $\left(\geq 39.6<40^{\circ} \mathrm{C}\right)$ to severe $\left(\geq 40^{\circ} \mathrm{C}\right)$ fever and the tongue lesions were severe, spreading beyond the sites of inoculation (Fig. 4A). However, the appearance of lesions on the hooves of the two cattle was delayed and mild compared to the placebo vaccinated controls (Fig. 4A).

Analyzing individual antibody kinetic data, we observed that neutralizing antibody titres of more than $2.0 \log _{10}$ were present in animals protected (mean titre $2.4 \pm 0.21, n=12$ ) and nonprotected $(2.06 \pm 0.11, n=2)$ at $21 \mathrm{dpv}$ (Fig. 3). Although IgG1 titres $(2.46 \pm 0.4)$ were higher than $\operatorname{IgG} 2$ titres $(2.11 \pm 0.3)$ in protected and non-protected animals, IgG2 titres were almost ten-fold lower in the non-protected animals $(1.7 \pm 0.4)$ (Fig. 3).

\subsection{Virus isolation and the presence of viral RNA}

FMDV was recovered from OP samples from one parental vaccinated and three chimera vaccinated animals at $2 \mathrm{dpc}$ (Table 1). Nasal samples of three of seven animals that received the parental vaccine were positive on virus isolation, but no virus could be isolated from nasal samples of the vSAT2 ${ }^{\text {ZIM14 }}$-SAT2 vaccinated group. Two of the animals from the parental vaccine group that were positive on virus isolation from nasal samples developed FMD lesions at sites other than the site of inoculation. In addition virus was also recovered from OP samples from one of two placebo vaccinated controls. No virus could be isolated from whole blood (Fig. 4).

FMDV RNA was detected by quantitative real time RT-PCR (positive sample $\mathrm{Ct}$ value $<40$ ) in OP samples taken from all seven SAT2/ZIM/14/90 vaccinated animals and from the two placebo vaccinated controls on $2 \mathrm{dpc}$ (Table 1 ) and up to $7 \mathrm{dpc}$ but were negative at $11 \mathrm{dpc}$. FMDV RNA was, however, detected in nasal samples from one of the seven animals in the parental vaccina-tion group (15-169; Table 1). Animals that received the chimera vaccine had viral RNA in the oropharynx between 2-7 dpc, but no viral RNA could be detected in the nasal samples (Table 1). FMDV RNA was also detected in whole blood ( $\mathrm{Ct}$ value $<40$ ) between $2-4$ $\mathrm{dpc}$ in five of seven parental and four of seven chimeric vaccinated animals and the placebo group (Fig. 4B). The viral RNA in whole blood of both vaccinated groups decreased as the antibody titres increased after challenge. High titres of anti-SAT2 antibodies $\left(>2.0 \log _{10}\right)$ were observed at $4 \mathrm{dpc}$ and remained high until the end of the experiment, with the exception of the placebo controls where sero-conversion only took place after 5-8 dpc. No viral RNA could be detected in whole blood of the vaccinated animals after 4 dpc.

\subsection{Cross-reactivity and predicted protection against heterologous field isolates}

In order to determine whether a vaccine prepared from SAT2/ZIM/14/90 or vSAT2 ZIM14-SAT2 is likely to protect cattle from challenge against heterologous viruses, serum neutralizing antibody titres were used to calculate the degree of predicted cross-protection (Table 2). The sera from either SAT2/ZIM/14/90 or vSAT2 ZIM14_SAT2 vaccinated groups ( $21 \mathrm{dpv}$ ) contained antibodies which were cross-reactive to the heterologous viruses causing recent outbreaks in the southern African region (Table 2 ). The virus neutralizing antibody responses generated against the homologous 
Table 1

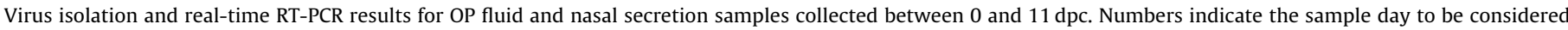
positive and () indicate Ct value ( $<40$ are considered positive).

\begin{tabular}{|c|c|c|c|c|c|c|}
\hline \multirow[t]{2}{*}{ Vaccine } & \multirow[t]{2}{*}{ Animal number } & \multirow{2}{*}{$\begin{array}{l}\text { Virus Isolation } \\
\text { OP fluid }\end{array}$} & \multicolumn{2}{|r|}{ rRT-PCR } & \multicolumn{2}{|r|}{ Clinical score $^{a}$} \\
\hline & & & Nasal & OP fluid & Nasal & \\
\hline \multirow{7}{*}{ SAT2/ZIM/14/90 } & 15-T7 & - & 2 & $2(22.5) ; 4(36.0)$ & - & $3(2,3,5,6)$ \\
\hline & 15-T25 & 2 & - & $2(34.8) ; 4(39.0)$ & - & 0 \\
\hline & 15-T29 & - & 2 & $2(21.2) ; 4(30.0)$ & - & 0 \\
\hline & 15-T32 & - & - & $2(34.8) ; 7(28.1)$ & - & 0 \\
\hline & 15-TD36 & - & - & $2(29.5) ; 4(31.8)$ & - & 0 \\
\hline & $15-169$ & 4 & 2 & $2(17.3) ; 7(31.1)$ & $2(36.4)$ & $3(2,3)$ \\
\hline & 15-NT2 & - & - & 2 (21.9); $4(32.7)$ & - & 0 \\
\hline \multirow[t]{7}{*}{ vSAT2 $2^{\text {ZIM14 }}$-SAT2 } & 16-TD16 & - & - & $2(38.7)$ & - & 0 \\
\hline & 16-TD20 & - & - & $2(39.7)$ & - & 0 \\
\hline & 16-TD25 & 2 & - & $2(24.3) ; 4(30.0)$ & - & 0 \\
\hline & 16-TD31 & 2 & - & $2(29.8) ; 4(28.8)$ & - & 0 \\
\hline & 16-TD37 & - & - & $4(37.9)$ & - & 0 \\
\hline & 16-TD41 & 2 & - & $2(32.8)$ & - & 0 \\
\hline & 16-NT1 & - & - & $7(38.2)$ & - & 0 \\
\hline \multirow[t]{2}{*}{ Placebo } & 12-T3 & - & - & $2(35.2) ; 4(28.0) ; 7$ (35.6) & - & $>10(4-13)$ \\
\hline & 12-T13 & 2 & - & $2(21.5) ; 4(28.2) ; 7(36.2)$ & - & $>10(4-11)$ \\
\hline
\end{tabular}

a Clinical scores were calculated as the total score on all the four hooves. The highest score is indicated and the dpc when they were recorded are in the parentheses ().

antigens were indistinguishable at 2.5 and $2.4 \log _{10}$ for SAT2/ZIM/14/90 or vSAT2 ZIM14-SAT2, respectively. However, the neutralizing antibody titres against the heterologous viruses varied between $1.8-2.4 \log _{10}$ and $1.5-2.6 \log _{10}$, respectively. The data in Table 2 shows that the neutralizing antibody titres of the 21dpv pooled sera from vSAT2 $2^{\text {ZIM14 }}$-SAT2 vaccinated animals against SAT2/ZIM/7/83 (1.49 $\left.\log _{10}\right)$ and SAT2/KNP/19/89 (1.48 $\left.\log _{10}\right)$ were below the cut-off value of $1.6 \log _{10}$.

The $r_{1}$-values, calculated as the ratio between the heterologous and homologous serum titres, indicate that the sera from the vaccinated animals cross-reacted sufficiently with the heterologous viruses to afford protection to these animals against challenge (Table 2 ). The $r_{1}$-values of SAT2/ZIM/14/90 or vSAT2ZIM14-SAT2 sera were $\geq 0.3$ against five of the eight viruses, indicating a close vaccine match. Of particular interest is the high cross-reaction of both the SAT2/ZIM/14/90 and the vSAT2 ${ }^{\text {ZIM14 }-S A T 2 ~ a n t i s e r a ~ t o ~}$ SAT2/SAR/1/10 (Table 2).

\section{Discussion}

In Africa, the antigenic diversity of circulating field strains of FMDV makes the selection of sufficiently cross-protective FMD

Table 2

Virus neutralization titres and predicted protection against heterologous field isolates.

\begin{tabular}{|c|c|c|c|c|}
\hline \multirow[t]{3}{*}{ Virus } & \multicolumn{4}{|c|}{ Serum } \\
\hline & \multicolumn{2}{|c|}{ SAT2/ZIM/14/90 } & \multicolumn{2}{|c|}{ vSAT2 ${ }^{\text {ZIM14 }}$-SAT2 } \\
\hline & $\mathrm{VNT}^{\mathrm{a}}$ & $r_{1}$-Value ${ }^{b}$ & $\mathrm{VNT}^{\mathrm{a}}$ & $r_{1}$-Value \\
\hline SAT2/ZIM/14/90 & 2.47 & 1 & 2.1 & 1 \\
\hline vSAT2 ${ }^{\text {ZIM14}}$ SAT2 & 2.97 & 1 & 2.39 & 1 \\
\hline SAT2/ZIM/7/83 & 1.82 & 0.27 & 1.49 & 0.28 \\
\hline SAT2/KNP/19/89 & 1.68 & 0.2 & 1.48 & 0.27 \\
\hline SAT2/SAR/3/04 & 1.93 & 0.35 & 1.94 & 0.36 \\
\hline SAT2/BOT/4/06 & 2.18 & 0.51 & 2.36 & 0.92 \\
\hline SAT2/NAM/1/07 & 1.92 & 0.29 & 1.97 & 0.37 \\
\hline SAT2/NAM/1/08 & 2.27 & 0.63 & 1.97 & 0.37 \\
\hline SAT2/SAR/1/10 & 2.44 & 0.93 & 2.63 & 1 \\
\hline SAT2/SAR/4/12 & 2.28 & 0.65 & 1.86 & 0.29 \\
\hline
\end{tabular}

a The $21 \mathrm{dpv}$ virus neutralization titres are expressed as $\log 10$ reciprocal antibody dilution required for $50 \%$ neutralization of 100 tissue culture infectious units. The mean values of two repeats are depicted.

b The $r_{1}$-values derived from $21 \mathrm{dpv}$ virus neutralising titres were calculated as the ratio between the heterologous and homologous serum titres and were interpreted as proposed by Samuel et al. [43]. $r_{1}$-Values $\geq 0.3$ were considered to sufficient cross-reactive to provide good protection. vaccines a challenge. Vaccines therefore need to be custom-made to be effective. One approach to address the problem of antigenic variation in the various epidemiological clusters $[2,44]$ would be the development of cross-serotype and intra-serotype chimeric vaccines [25]. The proposed strategy entails the development of chimeric FMDV by substituting antigenic-coding regions such as the external capsid proteins $(1 \mathrm{~B}-1 \mathrm{D} / 2 \mathrm{~A})$ in an infectious genomelength cDNA clone of a suitable strain [34]. The production of such recombinant viruses has been achieved for the A and SAT2 serotypes [26,30,33].

In the present study, the efficacy of an intra-serotype SAT2 chimeric vaccine was assessed. The chimeric virus produced this way was viable and stably maintained the $1 \mathrm{~B}-1 \mathrm{D} / 2 \mathrm{~A}$ sequence upon passage, indicating the surface-exposed capsid proteins are interchangeable between viruses of the same serotype. The vSAT2 ${ }^{\text {ZIM14 }}$-SAT2 virus exhibited comparable infection kinetics, virion stability and antigenic profiles to the SAT2/ZIM/14/90 parental virus. Viruses generated by reverse genetics provide the basis for the structural engineering of stabilised capsids, immunofocussing and optimised epitope representation.

Cattle vaccinated with the vSAT2 $2^{\text {ZIM14 }}$-SAT2 vaccine produced strong neutralizing antibody titres to the homologous parental virus, 2.1 to $2.8 \log _{10}$, at $21 \mathrm{dpv}$. However, the mean $\log _{10}$ neutralizing antibody titre in the chimeric vaccine group did not differ significantly from that in the parental vaccine group, 2.0 to $2.5 \log _{10}$, at $21 \mathrm{dpv}$. The data indicates that the chimeric antigen displayed the expected antigenicity and elicited neutralizing immunity, corresponding to the inserted capsid sequences. Following needle virus challenge at $21 \mathrm{dpv}$, all vSAT2 ${ }^{\text {ZIM14 }}$-SAT2 vaccinated cattle were protected, as determined by the absence of generalized lesions, even though viraemia and virus excretion in the oropharynx were detected between 2 and $4 \mathrm{dpc}$. On the contrary, the un-vaccinated controls and two of the parental vaccinated animals had developed pyrexia $24 \mathrm{~h}$ after challenge and generalized lesions within $48 \mathrm{~h}$ of challenge. These results combined with the VNT results further suggest that a single immunization with $6 \mu \mathrm{g}$ of the chimeric immunogen induced a significant FMDV-specific response in cattle and provided better protection than the parental vaccine.

The failure to correlate strong neutralizing antibody responses with protection from live virus challenge has been reported previously $[45,46]$. In our study the two mildly sick cattle that received the parental vaccine had $\log _{10}$ neutralizing titres of 2.1 and 2.0 at $21 \mathrm{dpv}$ and had detectable virus in the nasal cavity. Lavoria et al. [47] showed that IgG isotypes in a heterologous FMD response 
may provide complementary information to the VNT assessment following vaccination. In our study we have measured the homologous anti-FMD response in vaccinated cattle and that both IgG1 and IgG2 increased following FMD vaccination. However, the serum $\operatorname{IgG} 1$ was always higher than $\operatorname{IgG} 2$. There were varying $\operatorname{IgG} 1 / 2$ isotypes response patterns in non-protected animals. One of the animals in the parental vaccine group that showed systemic FMD had an IgG1 response but no IgG2 response, while the other ani-mal showed a much stronger $\operatorname{IgG} 1$ response compared to $\operatorname{IgG} 2$, in the presence of borderline positive VN titres. This data suggests that there are antibody mediated protective mechanisms besides neutralization that become evident when neutralizing antibodies titres are low or borderline positive. This may be as a result of other components of the host immune system such as cell-mediated immune response, the complement system and phagocytosis [46] or different clearing mechanisms associated with the different immunoglobulin isotypes or the absence of high avidity antibodies $[47,48]$ that were not accounted for in this study. We did not measured the antibody avidity or the role of cell-mediated response in this experiment and it is therefore not unreasonable to expect that the single immunization of cattle did not allow sufficient development of high avidity antibodies through affinity maturation or the development of optimal isotypes in some individual animals. The individual variation to vaccines is well documented and has been observed for chimeric vaccines as well [26,33].

The virus neutralising antibody titres from animals in the two different vaccination groups were then used to determine whether these vaccines were likely to protect cattle against recent outbreak viruses in southern Africa. The neutralizing antibody titres against the outbreak viruses were comparable to titres observed for SAT type vaccines that conferred protection in vivo [49]. From previ-ous work predicting protection using in vitro analysis and specific antibody responses [49] we can anticipate that $>88 \%$ of animals vac-cinated with either SAT2/ZIM/14/90 or vSAT2ZIM14-SAT2 vaccines would be protected against heterologous challenge with the viruses in this study. However, a different approach to predict protection using in vitro analysis and specific antibody responses has also been described by Brehm et al. [50]. Taking into consideration that we have vaccinated with SAT2 vaccines, the predicted protection of $>85 \%$ is based on the comparison of the SAT2 heterologous titres in this study with the protective titres in the study of Brehm et al.[50]. This also correlates with the predictions from Barnett et al.[49]. However, we have also included one-way antigenic relation-ship $\left(r_{1}\right)$ values which also showed a close vaccine match between SAT2/ZIM/14/90 or vSAT2ZIM14_SAT2 vaccinated sera and most of the outbreak viruses.

In this study the feasibility of an intra-serotype chimeric vaccine was assessed by determining the immunogenicity and protective ability following immunization of cattle. We have shown evidence that the intra-serotype chimera vaccine containing the surfaceexposed capsid proteins of a field strain acquired neutralizing antibodies that protect cattle against needle challenge with the field strain better than the parental vaccine. This supports the argument that custom-engineered chimeric FMD vaccines can be produced and applied in a fashion similar to the current inactivated vaccines for the control of FMD. Chimeric, genome-length clones could form the basis for the rational engineering of viruses with improved structural features as vaccine seed viruses. Viruses can be engi-neered with structurally stabilising mutations to be less reliant on a faultless cold chain [25,26,51], with BHK-21 cell culture adap-tation and increased antigen yield [31] or defective FMDV can be generated with deletions in various parts of the genome [52-54]. Furthermore, viruses can be engineered with modifications incorporated into the genome to support serological differentiation of infected from vaccinated animals [33] for surveillance of FMD in sub-Saharan Africa.

\section{Acknowledgements}

This work was supported by funding from MSD Animal Health (previously Intervet SPAH). The authors would like to express their sincere gratitude to Dr. D. Goovaerts and Dr. E. Rieder for many fruitful discussions, as well as the Brenda Botha and the diagnostic personnel at TADP of the ARC-OVI for assistance with the serology. Special thanks to Dr Alejandra Capozzo of INTA, Argentina for establishing the IgG isotype ELISA protocol in our laboratory, training to perform the assay and many fruitful discussions. Special thanks to Belinda Blignaut for her expertise in providing training in virus neutralization tests. Peninah Nsamba was a recipient of a fellowship from the Organization for Women in Science for the Developing World (OWSD) from 2007-2010. We thank Drs Mirinda van Kleef and Alri Pretorius for critical reading of the manuscript.

\section{References}

[1] Thompson D, Muriel P, Russell D, Osborne P, Bromley A, Rowland M, et al. Economic costs of the foot and mouth disease outbreak in the United Kingdom in 2001. Rev Sci Tech 2002;21:675-87.

[2] Rweyemamu M, Roeder P, MacKay D, Sumption K, Brownlie J, Leforban Y. Planning for the progressive control of foot-and-mouth disease worldwide. Transboundary Emerging Dis 2008;55:73-87.

[3] Alexandersen S, Kitching RP, Mansley LM, Donaldson AI. Clinical and laboratory investigations of five outbreaks of foot-and-mouth disease during the 200 epidemic in the United Kingdom. Vet Rec 2003;152:489-96.

[4] Rweyemamu M, Roeder P, Mackay D, Sumption K, Brownlie J, Leforban Y, et al. Epidemiological patterns of foot-and-mouth disease worldwide. Transboundary Emerging Dis 2008;55:57-72.

[5] Perry BD, Rich KM. Poverty impacts of foot-and-mouth disease and the poverty reduction implications of its control. Vet Rec 2007;160(7):238-41.

[6] Ferguson KJ, Cleaveland S, Haydon DT, Caron A, Kock RA, Lembo T, et al. Evaluating the potential for the environmentally sustainable control of foot and mouth disease in Sub-Saharan Africa. Ecohealth 2013;10:314-22.

[7] Miguel E, Grosbois V, Caron A, Cornelis D, Boulinier T, Foggin C, et al. Wildlifelivestock contacts: frequency of interactions contact and foot-and-mouth disease dynamic in cattle populations at the periphery of transfrontier conservation areas in Southern Africa. Ecosphere 2013;4:art51.

[8] Scoones I, Bishi A, Mapitse N, Moerane R, Penrith ML, Sibanda R, et al. Foot-andmouth disease and market access: challenges for the beef industry in southern Africa. Pastoralism 2010;1:135-64.

[9] Ayebazibwe C, Mwiine FN, Tjornehoj K, Balinda SN, Muwanika VB, Ademun Okurut AR, et al. The role of African buffalos (Syncerus caffer) in the maintenance of foot-and-mouth disease in Uganda. BMC Vet Res 2010;6:54.

[10] Bengis RG, Kock RA, Fischer J. Infectious animal diseases: the wildlife/livestock interface. Rev Sci Tech 2002;21:53-65.

[11] Condy JB, Hedger RS, Hamblin C, Barnett IT. The duration of the foot-and-mouth disease virus carrier state in African buffalo (i) in the individual animal and (ii) in a free-living herd. Comp Immunol Microbiol Infect Dis 1985;8:259-65.

[12] Hedger RS, Condy JB, Golding SM. Infection of some species of African wild life with foot-and-mouth disease virus. J Comp Pathol 1972;82:455-61.

[13] Vosloo W, Bastos AD, Kirkbride E, Esterhuysen JJ, van Rensburg DJ, Bengis RG, et al. Persistent infection of African buffalo (Syncerus caffer) with SAT-type foot-and-mouth disease viruses: rate of fixation of mutations, antigenic change and interspecies transmission. J Gen Virol 1996;77:1457-67.

[14] Bastos AD, Anderson EC, Bengis RG, Keet DF, Winterbach HK, Thomson GR. Molecular epidemiology of SAT3-type foot-and-mouth disease. Virus Genes 2003;27:283-90.

[15] Bastos AD, Haydon DT, Sangare O, Boshoff CI, Edrich JL, Thomson GR. The implications of virus diversity within the SAT 2 serotype for control of footand-mouth disease in sub-Saharan Africa. J Gen Virol 2003;84:1595-606.

[16] Bastos AD, Haydon DT, Forsberg R, Knowles NJ, Anderson EC, Bengis RG, et al. Genetic heterogeneity of SAT-1 type foot-and-mouth disease viruses in southern Africa. Arch Virol 2001;146:1537-51.

[17] Bastos AD, Boshoff CI, Keet DF, Bengis RG, Thomson GR. Natural transmission of foot-and-mouth disease virus between African buffalo (Syncerus caffer) and impala (Aepyceros melampus) in the Kruger National Park, South Africa. Epidemiol Infect 2000;124:591-8.

[18] Dawe PS, Flanagan FO, Madekurozwa RL, Sorensen KJ, Anderson EC, Foggin $\mathrm{CM}$, et al. Natural transmission of foot-and-mouth disease virus from African buffalo (Syncerus caffer) to cattle in a wildlife area of Zimbabwe. Vet Rec 1994;134:230-2.

[19] Thomson GR, Vosloo W, Bastos AD. Foot and mouth disease in wildlife. Virus Res 2003;91:145-61.

[20] Doel TR, Baccarini PJ. Thermal stability of foot-and-mouth disease virus. Arch Virol 1981;70:21-32.

[21] Bachrach HL. Foot-and-mouth disease. Annu Rev Microbiol 1968;22:201-44.

[22] Doel TR. FMD vaccines. Virus Res 2003;91:81-99. 
[23] Hunter P. Vaccination as a means of control of foot-and-mouth disease in subsaharan Africa. Vaccine 1998;16:261-4.

[24] Van Rensburg HG, Henry TM, Mason PW. Studies of genetically defined chimeras of a European type A virus and a South African Territories type 2 virus reveal growth determinants for foot-and-mouth disease virus. J Gen Virol 2004;85:61-8.

[25] Van Rensburg HG, Mason PW. Construction and evaluation of a recombinant foot-and-mouth disease virus: implications for inactivated vaccine production. Ann NY Acad Sci 2002;969:83-7.

[26] Blignaut B, Visser N, Theron J, Rieder E, Maree FF. Custom-engineered chimeric foot-and-mouth disease vaccine elicits protective immune responses in pigs. J Gen Virol 2011;92:849-59.

[27] Zibert A, Maass G, Strebel K, Falk MM, Beck E. Infectious foot-and-mouth disease virus derived from a cloned full-length cDNA. J Virol 1990;64:2467-73.

[28] Maree FF, Blignaut B, Esterhuysen JJ, de Beer TA, Theron J, O'Neill HG, et al. Predicting antigenic sites on the foot-and-mouth disease virus capsid of the South African Territories types using virus neutralization data. J Gen Virol 2011;92:2297-309.

[29] Piccone ME, Diaz-San Segundo F, Kramer E, Rodriguez LL, de los Santos T. Introduction of tag epitopes in the inter-AUG region of foot and mouth disease virus: effect on the L protein. Virus Res 2011;155:91-7.

[30] Rieder E, Baxt B, Lubroth J, Mason PW. Vaccines prepared from chimeras of footand-mouth disease virus (FMDV) induce neutralizing antibodies and protective immunity to multiple serotypes of FMDV. J Virol 1994;68:7092-8.

[31] Maree FF, Blignaut B, de Beer TA, Visser N, Rieder EA. Mapping of amino acid residues responsible for adhesion of cell culture-adapted foot-and-mouth disease SAT type viruses. Virus Res 2010;153:82-91.

[32] Storey P, Theron J, Maree FF, O'Neill HG. A second RGD motif in the 1D capsid protein of a SAT1 type foot-and-mouth disease virus field isolate is not essential for attachment to target cells. Virus Res 2007;124:184-92.

[33] Fowler VL, Paton DJ, Rieder E, Barnett PV. Chimeric foot-and-mouth disease viruses: evaluation of their efficacy as potential marker vaccines in cattle. Vaccine 2008;26:1982-9.

[34] Maree FF, Blignaut B, de Beer TA, Rieder E. Analysis of SAT type foot-andmouth disease virus capsid proteins and the identification of putative amino acid residues affecting virus stability. PLoS ONE 2013;8:e61612.

[35] Doel TR, Mowat GN. An international collaborative study on foot and mouth disease virus assay methods, 2. Quantification of $146 \mathrm{~S}$ particles. J Biol Stand 1985;13:335-44.

[36] OIE. Manual of diagnostic tests and vaccines for terrestrial animals. Paris:

Officenternational des Epizooties; 2012.

[37] Ferris NP, Donaldson AI. The world reference laboratory for foot and mouth disease: a review of thirty-three years of activity (1958-1991). Rev Sci Tech 1992;11:657-84.

[38] Roeder PL, Le Blanc Smith PM. Detection and typing of foot-and-mouth disease virus by enzyme-linked immunosorbent assay: a sensitive, rapid and reliable technique for primary diagnosis. Res Vet Sci 1987;43:225-32.

[39] Boom R, Sol CJ, Salimans MM, Jansen CL, Wertheim-van Dillen PM, van der Noordaa J. Rapid and simple method for purification of nucleic acids. J Clin Microbiol 1990;28:495-503.
[40] Bastos AD. Detection and characterization of foot-and-mouth disease virus in sub-Saharan Africa. Onderstepoort J Vet Res 1998;65:37-47.

[41] (a) Callahan JD, Brown F, Osorio FA, Sur JH, Kramer E, Long GW, et al. Use of a portable real-time reverse transcriptase-polymerase chain reaction assay for rapid detection of foot-and-mouth disease virus. J Am Vet Med Assoc 2002;220:1636-42;

(b) Capozzo AVE, Periolo OH, Robiolo B, Seki C, La Torre JL, Grigera PR. Total and isotype humoral responses in cattle vaccinated with foot and mouth disease virus immunogen produced either in bovine tongue tissue or BHK-21 cell suspension cultures. Vaccine 1997;15:624-30.

[42] Kärber G. Beitrag zur kollektiven Behandlung pharmakologischer reihenversuche. Path u Pharmakol 1931;162:480-3.

[43] Samuel AR, Ouldridge EJ, Arrowsmith AEM, Kitching RP, Knowles NJ. Antigenic analysis of serotype $\mathrm{O}$ foot-and-mouth disease virus isolates from the Middle East, 1981 to 1988. Vaccine 1990;8:390-6.

[44] Maree FF, Scott KA, Opperman PA, Chitray M, Sallu R, Sinkala Y, et al. Prospects for the control of foot-and-mouth disease: an African perspective. J Vet Med 2014.

[45] McCullough KC, Bruckner L, Schaffner R, Fraefel W, Muller HK, Kihm U. Relationship between the anti-FMD virus antibody reaction as measured by different assays, and protection in vivo against challenge infection. Vet Microbiol 1992;30:99-112.

[46] McCullough KC, De Simone F, Brocchi E, Capucci L, Crowther JR, Kihm U. Protective immune response against foot-and-mouth disease. J Viro 1992;66:1835-40.

[47] Lavoria MA, Di-Giacomo S, Bucafusco D, Franco-Mahecha OL, Perez-Filgueira DM, Capozzo AV. Avidity and subtyping of specific antibodies applied to the indirect assessment of heterologous protection against foot-and-mouth disease virus in cattle. Vaccine 2012;30:6845-50.

[48] Bucafusco D, Di Giacomo S, Pega J, Juncos MS, Schammas JM, Perez-Filgueira $\mathrm{M}$, et al. Influence of antibodies transferred by colostrum in the immune responses of calves to current foot-and-mouth disease vaccines. Vaccine 2014;32:6576-82.

[49] Barnett PV, Statham RJ, Vosloo W, Haydon DT. Foot-and-mouth disease vaccine potency testing: determination and statistical validation of a model using a serological approach. Vaccine 2003;21:3240-8.

[50] Brehm KE, Kumar N, Thulke HH, Haas B. High potency vaccines induce protection against heterologous challenge with foot-and-mouth disease virus Vaccine 2008;26:1681-7.

[51] Mateo R, Luna E, Rincon V, Mateu MG. Engineering viable foot-and-mouth disease viruses with increased thermostability as a step in the development of improved vaccines. J Virol 2008;82:12232-40.

[52] Falk MM, Sobrino F, Beck E. VPg gene amplification correlates with infective particle formation in foot-and-mouth disease virus. J Virol 1992;66:2251-60.

[53] Pacheco JM, Henry TM, O’Donnell VK, Gregory JB, Mason PW. Role of nonstructural proteins $3 \mathrm{~A}$ and $3 \mathrm{~B}$ in host range and pathogenicity of foot-and-mouth disease virus. J Virol 2003;77:13017-27.

[54] Piccone ME, Rieder E, Mason PW, Grubman MJ. The foot-and-mouth disease virus leader proteinase gene is not required for viral replication. J Virol 1995;69:5376-82. 